See Article page e143.

\section{Commentary: Potential advantages of terminal warm blood cardioplegia: Will the "hot shot" approach become hot stuff?}

\author{
Giuseppe Ambrosio, MD, PhD, FACC, FESC, \\ FAHA, ${ }^{\mathrm{a}}$ and GianFranco Gensini, $\mathrm{MD}^{\mathrm{b}}$
}

The search for optimal strategies to protect the arrested heart during cardiac surgery continues unabated. Current anesthesia and perioperative management protocols have made reperfusion-mediated injury upon declamping seem less of a problem. ${ }^{1,2}$ Yet cardiac arrest intrinsically carries with it deleterious effects on myocardial metabolism, particularly when prolonged beyond 60 minutes.

Many different approaches have been proposed to minimize this problem; however, research has been hampered by limitations when it comes to assess results. Differences in "hard" endpoints (eg, mortality) are difficult to explore in clinical trials owing to the huge sample size required and virtually impossible in experimental studies; thus, investigators have typically resorted to much "softer" endpoints, such as troponin release or incidence of arrhythmias following declamping. Clearly, this is unlikely to provide solid, satisfactory answers.

The study by Nakao and colleagues ${ }^{3}$ reported in this issue of the Journal goes a step forward. Using a left ventricular (LV) conductance catheter, they were able to precisely assess, in a load-independent fashion, LV contractile function through measurements of end-systolic elastance (\% Ees) and compliance via the end-diastolic pressurevolume relationship (\%EDPVR), to investigate in piglets the effects of warm-blood cardioplegia (TWBCP) administered at the end of a prolonged (120 minutes) single-dose

\footnotetext{
From the ${ }^{\mathrm{a}}$ Division of Cardiology, University of Perugia School of Medicine, Perugia, Italy and ${ }^{\mathrm{b}}$ Research Department, IRCCS MultiMedica, Milan, Italy.

Disclosures: The authors reported no conflicts of interest.

The Journal policy requires editors and reviewers to disclose conflicts of interest and to decline handling or reviewing manuscripts for which they may have a conflict of interest. The editors and reviewers of this article have no conflicts of interest.

Received for publication Dec 7, 2020; revisions received Dec 7, 2020; accepted for publication Dec 7, 2020; available ahead of print Jan 9, 2021.

Address for reprints: Giuseppe Ambrosio, MD, PhD, FACC, FESC, FAHA, University of Perugia School of Medicine, Ospedale S. Maria della Misericordia, Via S Andrea delle Fratte, 06156 Perugia, Italy (E-mail: giuseppe.ambrosio@unipg.it). J Thorac Cardiovasc Surg 2022;164:e157-8 $0022-5223 / \$ 36.00$

Copyright (C) 2020 by The American Association for Thoracic Surgery https://doi.org/10.1016/j.jtcvs.2020.12.046
}

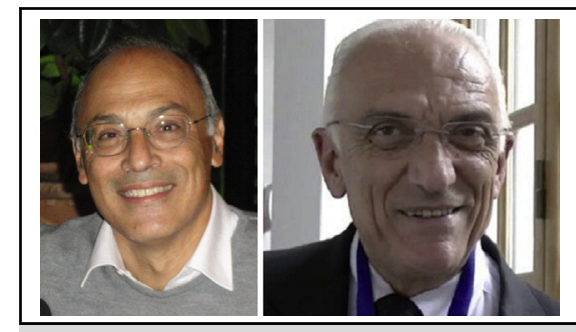

Giuseppe Ambrosio, MD, PhD, FACC, FESC, FAHA and GianFranco Gensini, MD

\section{CENTRAL MESSAGE \\ A shot of warm-blood cardio- plegia before declamping achieves prompt metabolic and contractile recovery of arrested hearts in an experimental model, as demonstrated by an objective assessment of function.}

cardioplegic arrest achieved with del Nido solution compared with del Nido cardioplegia alone. After a 150minute recovery, Ees was largely depressed in the del Nido group but substantially better in the TWBCP group $(57.9 \pm 17.8 \%$ vs $94.7 \pm 13.1 \% ; P<.028)$; EDPVR was also better in the TWBCP group $(88.5 \pm 24.0 \%$ vs $101.4 \pm 16.8 \% ; P=.050)$. These findings objectively support the authors' conclusions that a "hot shot" of warm cardioplegia before declamping on top of del Nido cardioplegia may allow safe prolongation of the arrest time up to 120 minutes.

On the mechanistic side, the authors complemented the study with data from cardiac biopsies, showing higher myocardial glycogen content in the TWBCP group, whereas mitochondria ultrastructure was altered only modestly and was similar in the 2 groups. The glycogen data hint at preserved glycolysis as a possible mechanism underpinning those results, ${ }^{4-6}$ whereas in the authors' model, preserved mitochondrial morphology might be indicative of myocardial "stunning", not of irreversible injury. ${ }^{7}$

Although interesting, these findings might not provide the ultimate answer as to the best cardiac protection strategy for prolonged arrest. Important issues are left unaddressed and/or require further research. Piglets are not human babies, let alone adult or elderly people-those in whom cardiac surgery is performed. In addition, these results apply 
only to a strategy of single-dosing del Nido cardioplegia; it is unknown whether a terminal "hot shot" maintains an edge when redosing and/or different cardioplegic solutions are used. Finally, as differences in LV function were documented just a few hours after declamping, it is possible that we might be looking at a speedier recovery rather than a persistent difference in cardiac function, as the finding of substantially preserved ultrastructure (consistent with stunning) might suggest.

In conclusion, Nakao and colleagues are to be commended for addressing an important issue through appropriate methodology. Specifically tailored studies in patients will demonstrate whether the hot shot approach will live up to its promise.

\section{References}

1. Milei J, Forcada CG, Grana DR, Iannelli G, Chiariello M, Tritto I, et al. Relationship among oxidative stress, lipid peroxidation, and ultrastructural damage in patients with coronary artery disease undergoing cardioplegic arrest/reperfusion. Cardiovasc Res. 2007;73:710-9.

2. Newman MF, Ferguson TB, White JA, Ambrosio G, Koglin J, Nussmeier NA, et al. RED-CABG Steering Committee and Investigators. Effect of adenosineregulating agent acadesine on morbidity and mortality associated with coronary artery bypass grafting: the RED-CABG randomized controlled trial. JAMA. 2012;308:157-64.

3. Nakao M, Morita K, Shinohara G, Saito S, Kunihara T. Superior restoration of left ventricular performance after prolonged single-dose Del Nido cardioplegia in conjunction with terminal warm blood cardioplegic reperfusion. J Thorac Cardiovasc Surg. 2022;164:e143-53.

4. Teoh KH, Christakis GT, Weisel RD, Fremes SE, Mickle DA, Romaschin AD, et al. Accelerated myocardial metabolic recovery with terminal warm blood cardioplegia. J Thorac Cardiovasc Surg. 1986;91:888-95.

5. Caputo M, Dihmis WC, Bryan AJ, Suleiman MS, Angelini GD. Warm blood hyperkalemic reperfusion ("hot shot") prevents myocardial substrate derangement in patients undergoing coronary artery bypass surgery. Eur J Cardiothorac Surg. 1998;13:559-64.

6. Jeremy RW, Ambrosio G, Pike MM, Jacobus WE, Becker LC. The functional recovery of post-ischemic myocardium requires glycolysis during early reperfusion. J Mol Cell Cardiol. 1993;25:261-76.

7. Milei J, Fraga CG, Grana DR, Ferreira R, Ambrosio G. Ultrastructural evidence of increased tolerance of hibernating myocardium to cardioplegic ischemiareperfusion injury. J Am Coll Cardiol. 2004;43:2329-36.
See Article page e143.

\section{Commentary: Del Nido cardioplegia with a "hot shot"}

\author{
Stephen J. Huddleston, MD, PhD, and \\ Rosemary F. Kelly, MD
}

In this issue of the Journal, Nakao and colleagues ${ }^{1}$ use a piglet model of cardiopulmonary bypass with Del Nido cardioplegic arrest to demonstrate enhanced early recovery of left ventricular function with administration of a dose of terminal warm blood cardioplegia (TWBCP, aka a "hot shot"). The physiologic effects of the combination of prolonged Del Nido cardioplegia followed by TWBCP have not been characterized in an experimental model previously. Designed to facilitate pediatric surgeries, Del Nido cardioplegia use in adult cardiac surgery is not commonly used.

From the Division of Cardiothoracic Surgery, Department of Surgery, University of Minnesota Medical School, Minneapolis, Minn.

Disclosures: The authors reported no conflicts of interest.

The Journal policy requires editors and reviewers to disclose conflicts of interest and to decline handling or reviewing manuscripts for which they may have a conflict of interest. The editors and reviewers of this article have no conflicts of interest.

Received for publication Dec 14, 2020; revisions received Dec 14, 2020; accepted for publication Dec 15, 2020; available ahead of print Dec 25, 2020.

Address for reprints: Rosemary F. Kelly, MD, 420 Delaware St SE, MMC 207, Minneapolis, MN 55455 (E-mail: kelly071@umn.edu).

J Thorac Cardiovasc Surg 2022;164:e158-9

$0022-5223 / \$ 36.00$

Copyright (c) 2020 by The American Association for Thoracic Surgery

https://doi.org/10.1016/j.jtcvs.2020.12.066
Check for updates

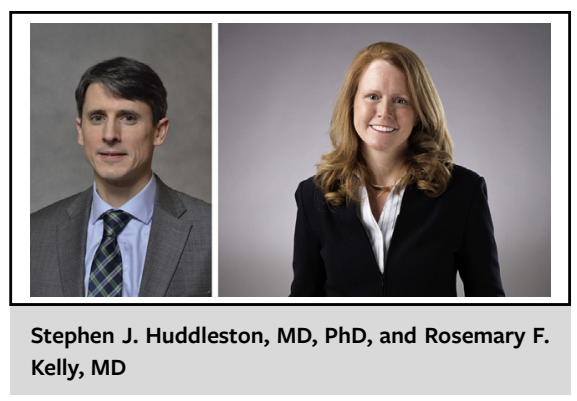

CENTRAL MESSAGE

Use of terminal normothermic

whole blood cardioplegia pro-

motes recovery of left ventricu-

lar contractility and compliance

after prolonged single-dose Del

Nido cardioplegic arrest.

The use of Del Nido cardioplegia in adult patients has been limited by concerns about increased arrhythmias, decreased contractility, and decreased glycogen stores outweighing the potential benefits of uninterrupted flow of the surgical procedure. ${ }^{2}$ However, if capable of comparable outcomes in the adult population, single-dose del Nido 